\title{
Assessing Outpatient Drug Abuse Treatment Programs
}

\author{
FRANK M. TIMS, ARTHUR M. HORTON, JR., \\ BENNETT W. FLETCHER, and RICHARD H. PRICE
}

Drug abuse is a major domestic health problem in the United States, and evaluators, policy makers, interest groups, and the general public are critically interested in knowing which treatments work best. Costs of drug abuse in America are conservatively estimated at 47 billion dollars per year (Harwood, 1984). It is estimated that over 27 million persons in households in the United States, or about one in every ten Americans, used illicit drugs in 1990 (National Institute on Drug Abuse, 1991).

The Drug Abuse Reporting Program (DARP) and the Treatment Outcome Prospective Study (TOPS) represent two major drug abuse treatment outcome studies. The DARP study tracked over 44,000 drug users admitted to 52 drug abuse treatment programs during 1969-1973. DARP found that demographic and socioeconomic characteristics explained only a small amount of outcome variance (Sells and Simpson, 1980). Better predictors of treatment outcome were the length of time in treatment and the behavior during treatment (Simpson et al., 1982).

TOPS included 11,750 drug users admitted to 41 drug abuse programs during 1979-1981. A finding from this study was that drug abuse treatment reduced illicit drug use and criminal behavior (Hubbard et al., 1989). As in DARP, time in treatment was positively related to drug abuse treatment outcome.

While the DARP and TOPS studies established the effectiveness of drug abuse treatment, many issues remain to be clarified. For example, more work is needed in efforts to match clients to treatment. The study of treatment process has remained tantalizingly difficult and little is known about the role that treatment structure and organization play in treatment outcome (Tims and Ludford, 1984).

The purpose of this paper is to report data about outpatient treatment unit followup evaluations drawn from selected evaluation items in the recent National Drug Abuse Treatment Survey. A section of questions related to treatment evaluation activities was included in this national survey of drug abuse treatment programs. These

Frank M. Tims, Arthur M. Horton, Jr, and Bennett W. Fletcher - Treatment Research Branch, National Institute on Drug Abuse. Rockville, MD 20857; Richard H. Price - Institute of Social Research, University of Michigan, 426 Thompson Street, Ann Arbor, MI $48106-1248$. 
questions provided information on a number of variables critical to program evaluation.

\section{METHOD}

This study uses self-report data from a national survey of outpatient drug abuse treatment units conducted in the Fall of 1988 by the University of Michigan's Institute for Social Research. 'The sample of units for the national study $(N=670)$ was a stratified random sample drawn from a list of the population of treatment units in the United States in $1988(N=6,851)$. The population of units was stratified according to treatment modality (methadone vs. non-methadone); ownership (public, private for-profit, private not-for-profit); and setting (hospital-based, mental health center based, freestanding facility).

The unit directors and clinical supervisors of each of the 670 selected treatment units were asked to complete phone surveys. Directors provided information concerning the unit's ownership, finances, and goals. Clinical supervisors provided information about staff members, clients, and services. The response rate was $85.8 \%(N=$ 575). Units not doing follow-up evaluation did not complete the evaluation questions. The number of usable respondents, i.e., those program directors who indicated they made some follow-up, was 377. The evaluation items of interest for this study were contained in Section "D" of the "Director"s Questionnaire." The major topics examined included the following:

- Follow-up Data Obtained

- Time Periods of Follow-up Data

- Successful Collection of Follow-up Data

- Types of Follow-up Data

- Means of Data Collection

- Changes Made

The response options were either a five part response menu that ranged from "no extent" to "a very high extent" or a yes/no format. Self-report data were not verified by actual visitation at the outpatient drug abuse treatment programs. The variables selected were related to collecting follow-up data after treatment ended. The variables assessed if, when, how, by whom, and what follow-up data were collected, as well as whether comparisons were made with other units, based on the follow-up data and changes made as a result of the comparisons.

\section{RESULTS}

The first and most notable finding is that only $66 \%$ of the units were collecting any follow-up data and only $27 \%$ said they were following up to any great extent. Future 
TABLE 1. At What Points Does Your Unit Typically Obtain Follow-up Information on Its Outpatient Substance Abuse Clients After They End Treatment?

\begin{tabular}{lcc}
\hline \multicolumn{1}{c}{ Time Period } & Percentage & Number of Units \\
\hline $1-3$ months & 60.2 & 227 \\
$4-6$ months & 45.9 & 17.3 \\
$7-9$ months & 11.1 & 42 \\
$10-12$ months & 34.7 & 131 \\
$13-18$ months & 6.6 & 25 \\
$19-24$ months & 4.8 & 18 \\
24 or more months & 3.4 & Total \\
& & 13 \\
\hline
\end{tabular}

research might concentrate on exploring what barricrs to the collection of follow-up data exist. If lack of resources is an issue, then financial incentives may prove helpful.

The largest number of follow-ups were conducted in the earliest time period (1-3 months) after the patient leaves treatment (Table 1); with fewer conducted as the time from termination lengthens ( 24 or more months). A third of the programs targeted a one-year follow-up interval, but less than one in ten programs $(8.2 \%)$ were collecting follow-up data longer than eighteen months after clients exited the program. Also, only $18 \%$ said they experienced success to any great extent in their follow-up efforts (Table 2).

The most frequently collected information $(96.5 \%)$ was post-treatment drug or alcohol use (Table 3). Other types of data collected by four out of five programs which collected any follow-up information (as reported by the program directors) were, in order of decreasing frequency: clients in recommended treatment $(89.9 \%)$, the client's employment status $(85.1 \%)$, the client's evaluation of the treatment experience $(81.4 \%)$, and the client's health status $(80.9 \%)$.

Of the various specifically identified methods, the most labor intensive method (face to face interviews) was the least often used (58.5\%). Less labor intensive methods such as telephone follow-up (75.3\%) and self-administered survey $(68.1 \%)$ were more frequently used (Table 4).

TABLE 2. To What Extent Is the Collection of Follow-up Data Successful for All Outpatient Substance Abuse Clients for Whom Your Unit Attempts to Obtain Follow-up

Data?

\begin{tabular}{lcc}
\hline \multicolumn{1}{c}{ Extent } & Percentage & Number of Units \\
\hline None & 2.7 & 10 \\
Little & 30.0 & 111 \\
Some & 49.5 & 183 \\
Great & 15.4 & 57 \\
Very great & 2.4 & Total \\
& & 370 \\
\hline
\end{tabular}


TABLE 3. Please Tell Me Which of the Following Kinds of Follow-up Information Are Obtained for Your Unit's Outpatient Substance Abuse Clients

\begin{tabular}{|c|c|c|}
\hline Data Type & Porrentage & Number of Units \\
\hline Drug or alcohol use & 96.5 & .36 .3 \\
\hline In recommended treatment & 89.9 & 338 \\
\hline Employment & 85.1 & 320 \\
\hline $\begin{array}{l}\text { Client evaluation of treatment } \\
\text { experience }\end{array}$ & 81.4 & 306 \\
\hline Health status & 80.9 & 304 \\
\hline Legal probation status & 76.9 & 289 \\
\hline Living arrangements & 71.5 & 269 \\
\hline $\begin{array}{l}\text { Client evaluation of the agency } \\
\text { in general }\end{array}$ & 69.7 & 262 \\
\hline $\begin{array}{l}\text { Information to get drop outs to } \\
\text { retum to treament }\end{array}$ & 67.3 & 253 \\
\hline Financial status & 51.1 & 192 \\
\hline Other intomation & 14.6 & 5.5 \\
\hline
\end{tabular}

TABLE 4. Is This Information Collected Through:

\begin{tabular}{lcc}
\multicolumn{1}{c}{ Meams } & Percentage & Number of Units \\
\hline Telephone follow-up & 75.3 & 287 \\
Self-adminstered surveys & 68.1 & 256 \\
Face-to-face interviews & 58.5 & 220 \\
Other & 26.9 & 101 \\
\hline
\end{tabular}

TABIE 5. To What Extent Does Your Unit Use This Follow-up Information to Make Changes in Your Outpatient Unit's Substance Abuse Programs?

\begin{tabular}{lcc}
\hline \multicolumn{1}{c}{ Extent } & Percentage & Number of Units \\
\hline None & 5.3 & 20 \\
Litlle & 12.6 & 47 \\
Some & 47.9 & 179 \\
Great & 31.3 & 117 \\
Very great & 2.9 & 11 \\
\hline
\end{tabular}

Clearly. the majority of programs collecting follow-up information were reported to make changes based on follow-up data, at least a "little" (94.7\%). Also, about one third $(34.2 \%)$ use follow-up data to make changes to a "great" or "very great" extent (Table 5). What sort of "changes" were made needs to be further explored. For example, different hours for program intake activities may be a "change," but it is not of the same order of magnitude as switching therapeutic modalities. 


\section{DISCUSSION}

These data are both cause for encouragement and cause for concern. In these days of cost containment and very tight budgets, that any sort of evaluations were conducted in drug abuse treatment programs is a hopeful sign. Indeed, many drug abuse programs are reported by program directors to be involved in evaluation activities. Many of these program directors may recognize the value of drug abuse treatment evaluation activities and be willing to devote a proportion of their scarce resources of time and personnel to collect follow-up data and make comparisons and changes. It would certainly be a hopeful development for the field of drug abuse treatment research if this perception were a reflection of the clinical reality (Tims and Ludford, 1984).

On the other hand, while many program directors report a degree of involvement in drug abuse treatment evaluation related activities, the extent of involvement is rarely very great. In all likelihood, scarcity of person-power and time are reasons for the less than ideal degree of evaluation activity in this area. More research, however, is needed to determine what other barriers exist to preclude effective drug abuse program evaluation. For example, an absence of technical expertise in program evaluation by regular program staff and the lack of appropriate evaluation instruments could be impediments to effective drug abuse treatment evaluation.

To further encourage evaluation efforts in the drug abuse field, a number of things could be done. For example, certification and licensing could be linked to meaningful involvement in evaluation, and, specific resources could be ear-marked for support of evaluation tasks. However, additional research needs to be conducted to determine what would encourage directors to conduct more meaningful evaluation activities.

Acknowledgments: This paper was prepared with data collected under National Institute on Drug Abuse Grant DA-03372. The authors wish to thank David Klingel for his assistance in data analysis.

\section{REFERENCES}

Harwood, H.J., Napolitano, D.M., Kristiansen, P.L., and Collins, J.J. (1984). Economic Costs to Society of Alcohol and Drug Ahuse and Mental Illness: 1980. Research Triangle Park, NC: Research Triangle Institute.

Hubbard, R.L., Marsden, M.E., Rachal, J.V., Harwood, H.J., Cavanaugh, E.R., and Ginzburg, H.M. (1989). Diug Abuse Treatment: A National Study of Effectiveness. Chapel Hill: University of North Carolina Press.

Leukefeld, C.G. and Tims, F.M. (1989). Relapse and recnvery in drug abuse: Research and practice. International Journal of the Addictions, 24(3), 189-201.

Simpson, D.D. (1981). Treatment for drug abuse; Follow-up outcomes and length of time spent. Archives of General Psychiatry, 38(8), 875-880.

Tims, F.M. and Ludford, J.P. (Eds.) (1984). Drug Abuse Treatment Evaluation: Strategies, Progress, and Prospects (NIDA Research Monograph No. 86). Rockville, MD: National Institute on Drug Abuse. 